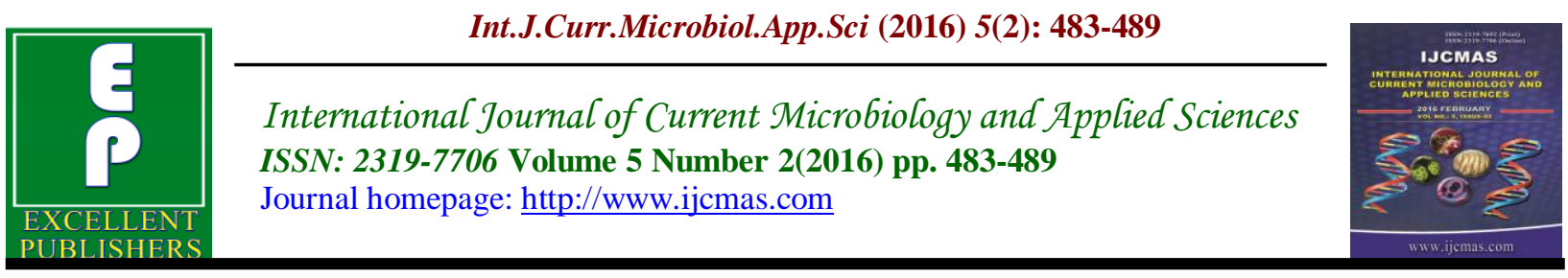

Original Research Article

doi: http://dx.doi.org/10.20546/ijcmas.2016.502.054

\title{
Chemical Composition and Anti-bacterial Effects of Clove (Syzygium aromaticum) Flowers
}

\author{
Khalid Abdul Kreem Mohammed $^{1 *}$, H. Mustafa Abdulkadhim ${ }^{2}$ and Sawsan I. Noori ${ }^{1}$ \\ ${ }^{1}$ Chemistry Department, College of Sciences, University of Baghdad, Baghdad, Iraq \\ ${ }^{2}$ Chemistry Department, College of Sciences, University of Kufa, Iraq \\ *Corresponding author
}

\begin{abstract}
A B S T R A C T
Keywords

Syzygium

aromaticum,

Chemical

Composition ,

Anti-bacterial

Effects of Clove

Article Info

Accepted:

25 January 2016

Available Online:

10, February 2016

The flower of Syzygium aromaticum (clove), a common food flavor, has been used as indigenous medicine for the treatment of several diseases in Asian countries. Safety assessment of $S$. aromaticum flower bud (clove) extract with respect to antimicrobial activity against two bacterial isolates. Moreover, the main work was characterizing the chemical components if alcoholic extract of $S$. aromaticum flower bud (clove) in terms of detection of Nitrogen, Sulfur, Halogens, Phenol, aldehydes, ketones and anthraquinones detection. Also Fourier Transform Infrared Spectroscopy (FTIR) and Ultraviolet (UV) spectrum analysis were used for attributing the extract. The result showed that the main composition of the extract was ketones and anthraquinones, the last one was responsible for biological activity of the extract. Furthermore, FTIR results showed morethan eight peaks for represent the main fine composition of the extract. UV spectrum showed that thae main absorption at 224, 268 and $348 \mathrm{~nm}$ due to the electronic transition from the type ${ }^{*} n-\pi$ for group of alcohol that bind with aromatic ring, * $n-\pi$ of group carbonyl bind with aromatic ring of quinone and $* \pi-\pi$ of the group of ketone that bind with aromatic ring. The present study also showed that the extract has antibacterial activity against two bacterial isolates Bacillus and Serratia marcescens.
\end{abstract}

\section{Introduction}

Syzygium aromaticum $(S . \quad$ aromaticum) (synonym: Eugenia cariophylata) commonly known as clove, is a median size tree. For centuries the trade of clove and the search of this valuable spice stimulated the economic development of this Asiatic region and agricultures in Asiatic region and it is used in different field of common life that is why playing a vital role in common life of different populations of different countries (1).
Clove is one of the major vegetal sources of phenolic compounds such as flavonoids, hidroxibenzoic acids, hidroxicinamic acids and hidroxiphenyl propens. The main bioactive compound of clove Eugenol is, which is found in concentrations ranging from 9381.70 to $14650.00 \mathrm{mg}$ per $100 \mathrm{~g}$ of fresh plant material (2). The phenolic acids and gallic acid are the compounds found in higher concentration. However, other gallic 
acid derivates as hidrolizable tannins are present in higher concentrations as compared with other compounds (3). Other phenolic acids found in clove are the caffeic, ferulic, elagic and salicylic acids. Flavonoids as kaempferol, quercetin and its group (glycosilated) are also found in clove but in lower concentrations. Concentrations up to $18 \%$ of essential oil can be found in the clove flower buds. Roughly, $89 \%$ of the clove essential oil is eugenol and $5 \%$ to $15 \%$ is eugenol acetate and $\beta$-cariofileno (4). Another important compound found in the essential oil of clove in concentrations up to $2.1 \%$ is $\alpha$-humulen. Other volatile compounds present in lower concentrations in clove essential oil are $\beta$-pinene, limonene, farnesol, benzaldehyde, 2-heptanone and ethyl hexanoate.

This plant has been used for centuries as food preservatives and as medicinal plants mainly as antioxidant agents and has antimicrobial activities. Recently, many reports confirmed the antibacterial, antifungal, antiviral and anticarcinogenic properties of this plant. Clove in particular has attracted the attention due to the potent antioxidant and antimicrobial activities standing out among the other spices (3). In current study, we focused on analysis of the chemical composition of the extract of flower of plant by Fourier Transform Infrared Spectroscopy (FTIR) analysis and UV spectrophotometer

\section{Materials and Methods}

\section{Praperation of Clove Extraction}

The standard method of Barre et al. was followed to prepare the Clove extraction. In this method $5 \mathrm{gm}$ of clove leaves was put in thumble flask and put in Soxhlet the extracted was done by ethanol for $25 \mathrm{~h}$. after that the extracted was separated from oil and stored for further experiments (5).

\section{Isolation of Clove (Syzygium aromaticum) Compounds}

Thin layer chromatography was used to isolate and separate the Clove (Syzygium aromaticum) compounds. In this technology silica gel $(200 * 200 * 2 \mathrm{~mm})$ plates (Merk) was used. Butand-Ethanal-Acetic acid $(5: 4: 1)$ was used as a solvent (6).

\section{Identification of Active Group of Clove Extract}

The active groups in clove extract were detected by TLC technology. The spotes was collected from gel and desolved in ethanol. The chemical composition was identified in inorganic chemistry in department of chemistry, college of education, University of Basarh, Iraq (7).

\section{Sodium Fusible}

Drops of clove extract were added to small piece of sodium in test tube. The mixture was heated to be red. Many drops of ethanol were added to cooled mixture. The mixture was heated again to deplete sodium and 4-5 drops of distilled water was added to cooled mixture. The mixture was boiled again and filtrated. The filtrated solution was used for the following experiment:

\section{Nitrogen Detection}

Drops of extract were put in test tube contained $0.2 \mathrm{gm}$ of ferric sulfate. The mixture was boiled to convert the $\mathrm{Fe}++$ to $\mathrm{Fe}+++$ after that diluted $\mathrm{H} 2 \mathrm{SO} 4$ was added to produce the blue complex.

\section{Sulfur Detection}

Acidification of extract with acetic acid and mixed with few drops of lead acetate to produce black precipitate of Lead sulfide. 


\section{Halogens Detection}

Acidification of the extract with few drops of HNO3 and mixed with silver nitrate to produce yellow precipitate.

\section{Phenol Detection}

In text tube, $2 \mathrm{ml}$ of the extract was mixed with few drops of Ferric chloride solution to produce purple solution.

\section{Detection of Aldehydes and Ketones}

The carbonyl group was detected by Brady's reagent (2,4-Dinitrophenylhydrazine) and alpha and aroma aldehydes group were detected by Tollen's reagent. In test tube, 2 $\mathrm{ml}$ of te extract was mixed with few drops of Brady's reagent after mixing the the appearing of black precipitate indication of positive results of presence of carbonyl group. Similarly, $2 \mathrm{ml}$ of the extract was mixed with few drops of Fehling's reagent and boiled the mixture for 2 minutes, red precipitate indication of aroma aldehydes. The detection of ketones was done by mixing $1 \mathrm{ml}$ of plant extract with few drops of sodium nitroprussid to produce red solution (6).

\section{Anthraquinones Detection}

Drops of the extract were mixed with drops of diluted sodium hydroxide with contentious agitation. The color of solution should be changed from brown to black because the oxidation effect in case of positive result (8).

\section{Fourier Transform Infrared Spectroscopy (FTIR) and Ultraviolet (UV) Spectrum Analysis}

\begin{tabular}{|c|c|}
\hline FT & (FT-IR-Pr \\
\hline
\end{tabular}

(shimadzu visible UV) analysis were done in the laboratories of College of Science, University of Kufa, Najaf, Iraq.

\section{Antibacterial Activity of Supernatant of Extract}

The antibacterial activity of the extract was done on two Isolates of bacteria, Bacillus and Serratia marcescens. Both of isolates were cultured into Muller Hinton broth prior to experiment (9). The disc diffusion method was used to assessment the antibacterial activity of the extract against Bacillus and Serratia marcescens. Briefly, filter paper of Whatman no1 was cut to circles with $0.5 \mathrm{~cm}$ in diameter and then sterile by autoclave. The piece of papers were dried and submerged in different dilution of the extract $(1,1 / 2,1 / 3 ; \mathrm{V} / \mathrm{V})$. after overnight the paper $\mathrm{s}$ were dried by oven at $37{ }^{\circ} \mathrm{C}$ for $20 \mathrm{~min}$. Each bacterial isolate was spread onto Muller Hinton agar and left upright for $2 \mathrm{~h}$. The prepared papers were put onto plates and incubated at $37{ }^{\circ} \mathrm{C}$ for overnight. The results were observed by clear zone around the discs (8).

\section{Results and Discussion}

Extraction, Separation and Purification of Chemical Compounds from Clove (Syzygium aromaticum) Flowers

The extraction was done by Soxhlet with ethanol. By this method the oil components were depleted. In extraction it was observed white pellet, after extraction the yielded extract was oil free. The final extract was run by TLC. By the last technology, many spots were observed and the spots were scratched and the chemical components were extracted by ethanol. Finally, it was gained the alcoholic extraction of clove that used in further experiments (9). Several previous studies focused on the extraction of 
different compounds from clove (Syzygium aromaticum) flowers and used in different fields of medicine. They found that the extract of clove (Syzygium aromaticum) composed from wide spectrum of chemical components and most of them were safe (10).

Table.1 Inhibition Zone that Produced by Alcoholic Extract of Clove (Syzygium aromaticum) Flower against Bacillus and Serratia marcescens Isolates

\begin{tabular}{|l|c|c|c|c|}
\hline \multirow{2}{*}{ Bacteria } & \multicolumn{4}{|c|}{ Dilution of the extract } \\
\cline { 2 - 5 } & 1 & $1 / 2$ & $1 / 3$ & Control \\
\hline Serratia & $18.3 \mathrm{~mm}$ & 12.4 & $9 \mathrm{~mm}$ & $0 \mathrm{~mm}$ \\
marcescens & & $\mathrm{mm}$ & & $0 \mathrm{~mm}$ \\
\hline Bacillus & 14.9 & 11.6 & $8 \mathrm{~mm}$ & \\
& $\mathrm{~mm}$ & $\mathrm{~mm}$ & & \\
\hline
\end{tabular}

Fig.1 Ftir Analysis of Alcoholic Extract of Clove (Syzygium aromaticum) Flower. Ftir Analysis of the Extract Showed more than 8 Peaks of Bands

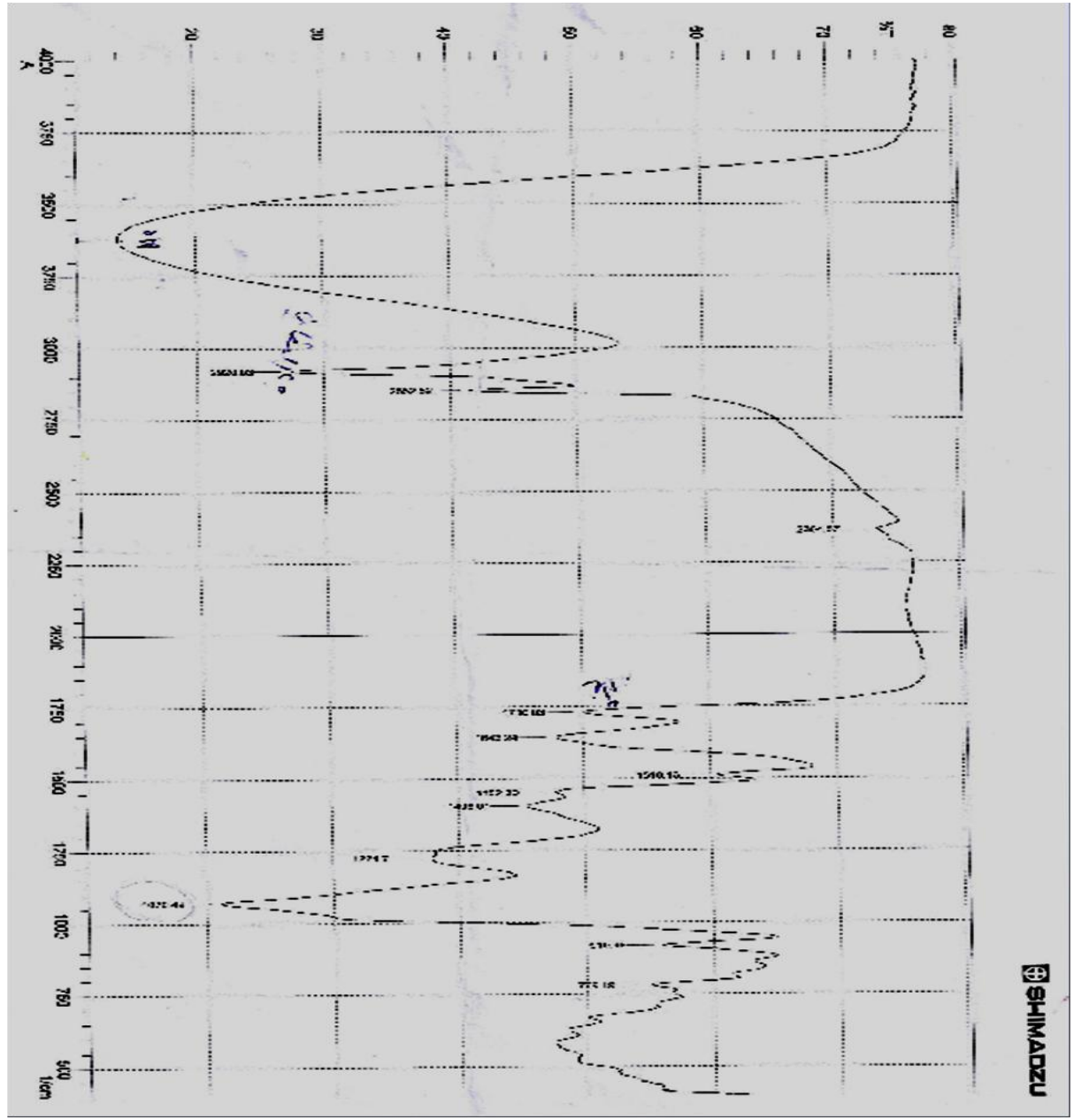


Fig.2 UV Spectrum Analysis of Alcoholic Extract of Clove (Syzygium aromaticum) Flower

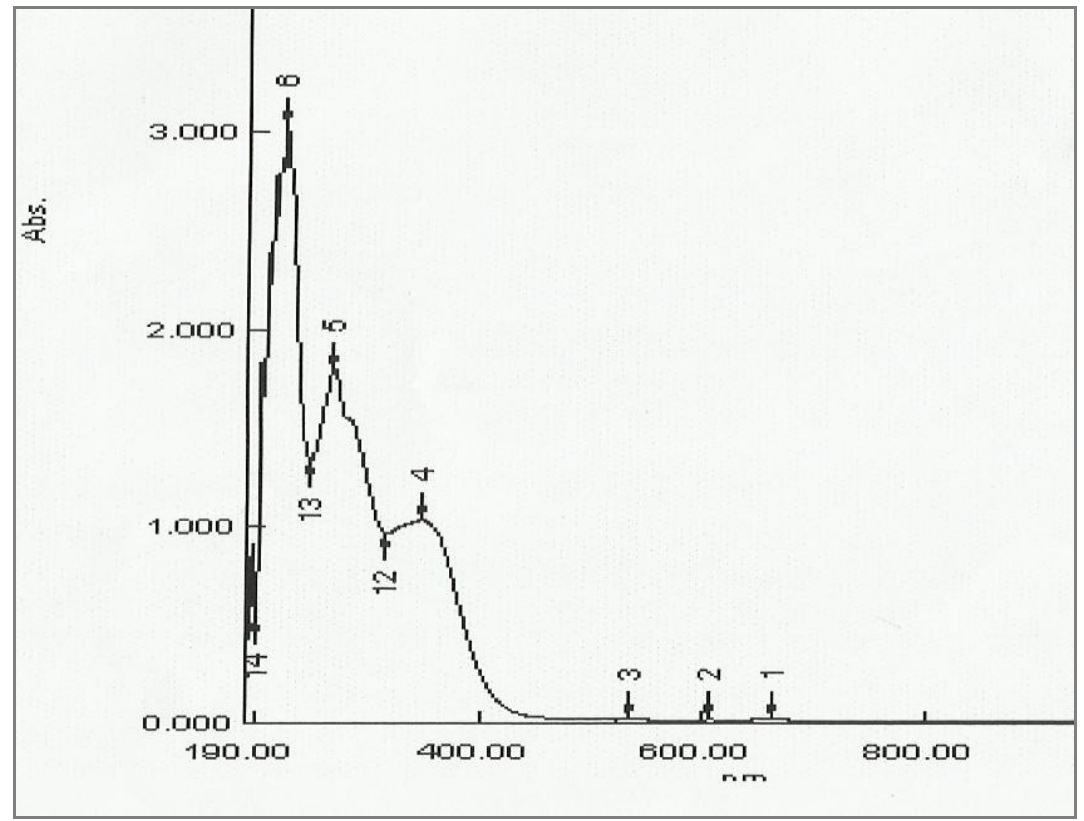

Identification of Alcoholic Extract of Clove (Syzygium aromaticum) Flower

The identification tests of the extract gave good and clear results. Identification tests for Sulfur, Halogens, Phenolic compounds and aldehydes gave negative results. These are going on with results of previous study (11). However, ketones detection test gave positive result by giving red solution in the end of reaction. The anthraquinones detection test is the highly valuable test because we did not find any researcher used this test in spite of the role of anthraquinones in biological activity (antibacterial activity) in alcoholic extract of clove (Syzygium aromaticum) flower. In present study this test gave positive results because the oxidation process $(8,12)$.

\section{FTIR Analysis}

The results of FTIR analysis showed that there is a clear and high intensive band $(3375 / \mathrm{cm})$ which represent $\mathrm{OH}$ groups of alcoholic extract. The moderate band (2920$2852 / \mathrm{cm})$ that represents frequency asymmetrical patterns of group $\mathrm{CH} 2$ and $\mathrm{CH} 3$ of alcoholic compound. Another band $(1730 / \mathrm{cm})$ represented frequency patterns of ester group $\mathrm{C}-\mathrm{O}$ or aromic ketone group $\mathrm{C}=\mathrm{O}$ which combine with more than ring. The band $1643 / \mathrm{cm}$ which is also the patterns match the frequency of the aromatic carbonyl group belonging to quinine (13) which nearby and similar to aromatic group $(\mathrm{C}=\mathrm{C})$. The bands at $1452 / \mathrm{cm}$ and $1402 / \mathrm{cm}$ represents the frequency of pattern of group CH2- and other strong band $(1070 / \mathrm{cm})$ which represents frequency of pattern of group C-O. Another moderate bands at 779 $/ \mathrm{cm}$ and $919 / \mathrm{cm}$ that represents the frequency of pattern of groups $\mathrm{CH} 2$ and $\mathrm{C}=\mathrm{C}$, respectively $(14)$.

\section{UV Spectrum Analysis}

Fig 2 showed results of UV spectrum analysis for alcoholic extract of clove (Syzygium aromaticum) flower. The absorption at $224 \mathrm{~nm}$ due to the electronic transition from the type $* n-\pi$ for group of alcohol that bind with aromatic ring and absorption at $268 \mathrm{~nm}$ is due to electronic 
move of type $* n-\pi$ of group carbonyl bind with aromatic ring of quinone which reach up to $350 \mathrm{~nm}$ and give the yellow color of these compounds. Absorption at $348 \mathrm{~nm}$ is belonging to the electronic moving of the type $* \pi-\pi$ of the group of ketone that bind with aromatic ring (15).

\section{Antibacterial Activity of Alcoholic Extract of Clove (Syzygium aromaticum) Flower}

Table 1 showed the antibacterial activity of alcoholic extract of clove (Syzygium aromaticum) flower against two bacterial isolates. The results showed that the extract reduced the bacterial growth and the diameter of clear zone realted positively with the concentration of the extract. That is why the lowest diameter was observed in case of the highest dilution of extract (1/3). The extract showed highly effect on bacterial growth that because the presence of active groups of quinone in the extract. That play important role in the inhibition process to the content of the carbonyl group of atoms oxygen that the presence of the duples of electronic that react or link with enzymes of active groups in the body of the host, which lead to the inhibition of some important enzymes, as well to what the duty of ketones group (16).

\section{References}

1. Kamatou GP, Vermaak I, Viljoen AM. Eugenol--from the remote Maluku Islands to the international market place: a review of a remarkable and versatile

molecule. Molecules. 2012;17(6):69536981.

2. Neveu V, Perez-Jiménez J, Vos F, Crespy V, du Chaffaut L, Mennen L, et al. Phenol-Explorer: an online comprehensive database on polyphenol contents in foods. doi: 10.1093/database/ bap024.

3. Shan B, Cai YZ, Sun M, Corke H. Antioxidant capacity of 26 spice extracts and characterization of their phenolic constituents. J Agric Food Chem 2005; 53(20): 7749-7759.

4. Jirovetz L, Buchbauer G, Stoilova I, Stoyanova A, Krastanov A, Schmidt E. Chemical composition and antioxidant properties of clove leaf essential oil. J Agric Food Chem 2006; 54(17): 63036307.

5. Barre JT, Bowden BF, Coll JC, Dejesus J, Delafuente VE, Janairo GC, Ragasa CY. (1997) A bioactive triterpene from lantana-camara. Phytochemis 45: 321324.

6. Deintrop EH. (2007) Applied ThinLayer chromatography, WileyVchVerlag $\mathrm{GmbH}$ and Co. KGaA, Weinheim.

7. Shriner RL, et al. (2004) The systematic identification of organic compounds. John Wiley and Sons. Inc.

8. Hepworth JD, Waring DR, Waring MJ, Berry M, Drayton C. (2002) Aromatic Chemistry, The Royal Society of Chemistry, Cambridge: 176.

9. Nana WL, Eke P, Fokom R, BakanrgaVia I, Begoude D, Tchana T, Tchameni NS, Kuate J, Menut C, Boyom FF. (2015) Antimicrobial Activity of Syzygium

aromaticum and Zanthoxylum

xanthoxyloides essential oils against Phytophthora megakarya. J Phytopathol 163: 632-641.

10. Mishra R, Singh SK. (2008) Safety assessment of Syzygium aromaticum flower bud (clove) extract with respect to testicular function in mice. Food and Chemical Toxicology 46:3333-8.

11. Aronson JK, Phil MAD. (2009) Meyler's side effects of herbal medicines, Oxford, United Kingdom. 
12. Mistry BD. (2009), A Hand book of Spectroscopic Data Chemistry, OxfordBook CompanyJaipur, India.

13. Silverstein RM et al. (2005), Spectrometric Identification of organic compounds, John Wiley and Sons. Inc.

14. Whittaker D. (2000), Interpreting Organic Spectra. The Royal Society of Chemistry.
15. Sarker SD, Nahar L. (2007) Chemistry for Pharmacy Students, John Wiley \& Sons Ltd: 142.

16. Tojo G, Ferna'ndez M. (2002) Oxidation of alcohols to aldehydes and ketones, Springer ScienceBusiness Media, Inc: 208-238.

\section{How to cite this article:}

Khalid Abdul Kreem Mohammed, H. Mustafa Abdulkadhim and Sawsan I. Noori. 2016. Chemical Composition and Anti-bacterial Effects of Clove (Syzygium aromaticum) Flowers Int.J.Curr.Microbiol.App.Sci.5(2): 483-489. doi: http://dx.doi.org/10.20546/ijcmas.2016.502.054 